\title{
O TRABALHO DOCENTE NAS CLASSES HOSPITALARES: SOLIDARIEDADE E AMOR
}

\section{TEACHING WORK IN THE HOSPITAL CLASSES: SOLIDARITY AND LOVE}

\section{José Rosamilton de Lima ${ }^{1}$}

RESUMO: A pedagogia hospitalar é uma área da educação especial que visa atender pessoas que tem uma necessidade pessoal transitória causada por doença e que se encontram afastadas da escola. As classes hospitalares devem proporcionar um ambiente descontraído em que estejam presentes brinquedos, jogos, quadros coloridos, figuras, estímulos visuais, computadores, notebooks, tabletes, figuras, cartazes, mapas, livros, revistas, entre outros. O pedagogo promove aprendizagem dentro ou fora do ambiente escolar, oferecendo ao aluno conhecimento e informação, como também, desenvolve estratégias para proporcionar um aprendizado significativo para a vida do estudante no tocante a sua formação humana. Este artigo objetiva discutir o trabalho docente nas classes hospitalares como forma de provocar uma reflexão a respeito da educação inclusiva no Brasil. Utilizou-se como referencial teórico a Resolução 01/2006 do CNE, as DNEE (2001), a Constituição Federal (1998), Oliveira (2013), Fontes $(2004 ; 2008)$ entre outros. O bom relacionamento entre o pedagogo hospitalar e o aluno/paciente é essencial para a construção de um ambiente seguro, confortável e propício para o ensino-aprendizagem, e consequentemente, ajuda em uma melhoria na recuperação da saúde do enfermo, porque encoraja ele para um enfrentamento com maior determinação. Portanto, é importante a implementação de classes hospitalares pelo Brasil, visto que existem muitas crianças e adolescentes que ainda não são contempladas com essa prestação de serviço.

PALAVRAS-CHAVE: Classes hospitalares. Pedagogo hospitalar. Aluno/paciente.

ABSTRACT: The hospital pedagogy is an area of the special education that aims to attend people that have a necessity transient personal need caused by disease and who are away from school. The hospital classes should provide a relaxed atmosphere with toys, games, colored frames, maps, books, magazines, among others. The pedagogue promotes learning in or out of school, offering to student knowledge and information, as well as, develops strategies to provide a meaningful learning to student's life related his human formation. This article aims to discuss the teacher work in the hospital classes as a way to provoke a reflection about inclusive education in Brazil. It was used as theoretical reference the Resolution 01/2006 of the CNE, the DNEE (2001), the Federal Constitution (1998), Oliveira (2013), Fontes (2004; 2008) among others. The good relationship between the hospital pedagogue and the student/patient is essential to the construction of a conducive, comfortable and secure atmosphere to teaching and learning, and consequently, help to a best recuperation of patient's health, because encourage him to a confrontation with a greater determination. Therefore, is important the implementation of hospital classes in Brazil, since there are many children and teenagers who are not yet contemplated with this service provision.

\footnotetext{
${ }^{1}$ Mestre em Letras pela Universidade do Estado do Rio Grande do Norte. Graduando do Curso de Pedagogia da Faculdade Anhanguera. Email: rosamiltonlima@ hotmail.com

Saberes Pedagógicos, Criciúma, v. 5, nº 1, janeiro/abril 2021. - Curso de Pedagogia - UNESC
} 
KEYWORDS: Hospital classes. Hospital pedagogue. Student/patient.

\section{CONSIDERAÇÕES INICIAIS}

A Constituição Brasileira de 1988 delimita que toda criança e adolescente tem direito a educação e a saúde. Para realização de tratamento de saúde é necessário internamento em um hospital ou visitas que ocorrem diária ou semanalmente. Entretanto, quando está impossibilitado de ir à escola e se afasta para cuidar de sua saúde, o aluno/paciente não pode deixar de receber educação em um período que se encontra enfermo, estando fragilizado física e emocionalmente. É importante que os pais tenham conhecimento desse direito das crianças e adolescentes e busquem saber das parcerias dos hospitais com as escolas para solicitarem junto ao órgão competente a prestação desse serviço.

As classes hospitalares foram criadas para que possa ser garantido o direito de estudar para toda criança e adolescente promulgado constitucionalmente, mesmo que estejam afastadas da escola por problemas de saúde. Elas propõem o acompanhamento pedagógico-educacional que acontece em ambiente de tratamento de saúde quando o aluno está internado ou necessita ir com frequência ao hospital. Logo, o gosto pelo aprendizado pode ajudar na autoestima do aluno/paciente, e consequentemente, pode influenciar de forma significativa para uma recuperação mais rápida da criança e adolescente que se encontra com alguma enfermidade.

É interessante mencionar que a pedagogia hospitalar é uma área da educação especial que visa atender pessoas que tem uma necessidade pessoal transitória causada por doença e que se encontram afastadas da escola. Dessa forma, são desenvolvidas atividades tanto na biblioteca hospitalar como em classes hospitalares. Trata-se de um espaço privilegiado porque tem como objetivo humanizar e proporcionar condições para a recuperação do paciente, dando um suporte psicológico e na saúde física. Então, as classes hospitalares devem proporcionar um ambiente descontraído em que estejam presentes brinquedos, jogos, quadros coloridos, figuras, estímulos visuais, computadores, notebooks, tabletes, figuras, cartazes, mapas, livros, revistas, entre outros.

Vale ressaltar que no hospital a criança se distancia de sua rotina regular do convívio familiar, das brincadeiras com seus amigos, do ambiente escolar e passa a conviver num espaço

Saberes Pedagógicos, Criciúma, v. 5, nº 1, janeiro/abril 2021. - Curso de Pedagogia - UNESC 


\section{SABERES PEDAGÓGICOS}

Revista do Curso de Graduaçào de Pedagogia - Unesc

ISSN 2526-4559

hostil, de isolamento e tristeza. Nesta ocasião, é necessário o apoio familiar e a existência de classes hospitalares para alegrar o ambiente e encorajar a criança e o adolescente a não perder o gosto de viver. Para que ocorra uma maior presença de classes hospitalares no Brasil são necessárias políticas públicas resultantes de pressões da sociedade para que o governo implemente com eficiência essa prestação de serviço à população brasileira.

Este artigo objetiva discutir o trabalho docente nas classes hospitalares como forma de provocar uma reflexão a respeito da educação inclusiva no Brasil. Para tanto, além das considerações iniciais e finais este trabalho está dividido em quatro partes. Na primeira parte, situa-se a pedagogia hospitalar como uma importante ramificação da pedagogia responsável para promoção de uma ação inclusiva, abordando a função do pedagogo hospitalar. Na segunda, apresenta-se de forma breve o desenvolvimento histórico das classes hospitalares, enfatizando seu surgimento e sua definição, ao mesmo tempo em que menciona-se sua relevância. Na terceira, relaciona-se as referidas classes com as políticas de educação inclusiva no Brasil e problematiza-se os aspectos da formação docente que perpassam o exercício e a prática da docência no universo hospitalar. Por fim, na quarta parte relata-se a importância do vínculo entre o professor, a família e o aluno/paciente nas classes hospitalares, visando um desenvolvimento global do mesmo.

\section{PEDAGOGIA HOSPITALAR: UMA AÇÃO DE INCLUSÃO}

O pedagogo é aquele que promove aprendizagem dentro ou fora do ambiente escolar, oferecendo ao aluno conhecimento e informação, assim como, desenvolve estratégias para proporcionar um aprendizado significativo para a vida do estudante no tocante a sua formação humana. De acordo com o $4^{\circ}$ parágrafo, da Resolução CNE/CP Nº 1 , de 15 de maio de 2006,

O curso de Licenciatura em Pedagogia destina-se à formação de professores para exercer funções de magistério na Educação Infantil e nos anos iniciais do Ensino Fundamental, nos cursos de Ensino Médio, na modalidade Normal, de Educação Profissional na área de serviços e apoio escolar e em outras áreas nas quais sejam previstos conhecimentos pedagógicos. 
Como pode ser visto, a partir da Resolução 01/2006 do CNE foi possível uma abertura para que o pedagogo possa trabalhar em diversas áreas. Dentre todas essas possibilidades, é muito importante a atuação do pedagogo em classes hospitalares, porque permite o desenvolvimento de práticas pedagógicas em um ambiente em que existe pessoas necessitando de cuidados especiais no tocante a aprendizagem, e que simultaneamente está lutando para tratar de enfermidades.

O pedagogo deve demonstrar conhecimentos e habilidades que estimulem a autoestima do aluno/paciente, trabalhando com atividades lúdicas que facilitem a aprendizagem do educando, e consequentemente, traga alegria para ajudar no tratamento de saúde. Ademais, há o esforço para que essa criança e/ou adolescente possa retornar a escola sem perder o ano letivo. Pois, para que esse objetivo seja alcançado é relevante o apoio familiar com atenção, afetividade e incentivo. Esse é um fator fundamental para que a criança não se sinta triste e que adquira forças psicológicas para enfrentar a doença.

Então, o pedagogo além de trabalhar em sala de aula na educação infantil e nos anos iniciais do ensino fundamental, ele pode trabalhar na administração escolar (supervisão, coordenação, direção), na educação especial (intérprete de Libras, professor auxiliar para alunos com necessidade especial), empresas (promovendo reconstrução de conceitos básicos, como criatividade e espírito de equipe), hospitais, postos de saúde, atuar na área da tecnologia (desenvolvedores de jogos e programas educativos), editoras (elaborando materiais didáticos e livros infantis), pesquisas científicas, dentre outros.

A Pedagogia Hospitalar é uma ação de educação inclusiva, que existe para facilitar a inclusão de crianças e adolescentes hospitalizadas que se ausentaram da sala de aula por motivo de doenças, fazendo com que os alunos não se sintam descriminalizados por não poderem comparecer na escola. Trata-se de uma modalidade de ensino no ambiente hospitalar direcionada a crianças e adolescentes, sendo breve ou longo o período da internação, visando a continuidade do estudo, ainda que o ambiente seja diferente e a metodologia menos rígida, cheias de ludicidade, para amenizar o ambiente triste de um hospital.

É importante que o pedagogo hospitalar tenha conhecimentos sobre doenças e do estado físico e psicológico do aluno. Assim, ele vai saber quais atividades devem ser trabalhadas para auxiliar no seu desenvolvimento intelectual e afetivo. Nesse sentido, o conteúdo deve ser

Saberes Pedagógicos, Criciúma, v. 5, nº 1, janeiro/abril 2021. - Curso de Pedagogia - UNESC 


\section{SABERES PEDAGÓGICOS}

Revista do Curso de Graduaçào de Pedagogia - Unesc

ISSN 2526-4559

contemplado de forma semelhante como era na escola, sem a exclusão de assuntos importantes, sendo que o estímulo intelectual deve ocorrer por meio de atividades lúdicas, materiais de apoio, uso de computador e outros. A família deve estar sempre presente na integração do hospital com a escola.

Com base no exposto, a pedagogia hospitalar é fundamental para a inclusão do aluno enfermo para a não evasão escolar. Pois, o aluno afastado da escola para tratamento de saúde deve receber apoio de um pedagogo hospitalar para acompanhamento de suas atividades escolares para que ele não perda o aluno letivo. Entretanto, deve haver estratégias que proporcione uma aprendizagem eficiente nesse momento de fragilidade física e psicológica.

Vários projetos da pedagogia hospitalar são desenvolvidos pelas Organizações Não Governamentais - ONGs. Elas não possuem vínculos com o governo e são responsáveis por trabalhos sociais e políticos, ou seja, promovem ações que tem por objetivo o bem de pessoas, animais, ambientes, entre outros. Neste caso, essas ONGs não possuem a intenção de gerar lucros, porque almejam apenas promover trabalhos benéficos e justiça social para as pessoas.

Nesse sentido, são exemplos de projetos desenvolvidos por ONGs os doutores da alegria, que são profissionais de saúde vestidos de palhaços que fazem visitas para as crianças e adolescentes enfermas, trazendo brincadeiras, paródias e muitas alegrias a esses pacientes internados. Os doutores da alegria tem como missão ser uma organização proeminentemente dedicada a levar esperança para as crianças hospitalizadas, seus pais e profissionais de saúde, através da arte do palhaço, nutrindo essa forma de expressão como meio de enriquecimento da experiência humana.

Dessa forma, a pedagogia hospitalar está presente por meio da brinquedoteca, apresentações musicais, teatrais, visitas de pessoas famosas, contação de histórias, jogos em grupos, leituras, brincadeiras, dinâmicas, atividades de desenhos, arte, pinturas, etc. O pedagogo hospitalar, junto com a família e os profissionais do hospital possuem um papel essencial para a melhoria da autoestima da criança, como também, para sua aprendizagem e recuperação de sua saúde.

Saberes Pedagógicos, Criciúma, v. 5, nº 1, janeiro/abril 2021. - Curso de Pedagogia - UNESC 


\section{AS CLASSES HOSPITALARES: SURGIMENTO, DEFINIÇÃO E IMPORTÂNCIA}

Embora há relatos de que no Brasil colônia por volta de 1600 já havia atendimento escolar aos deficientes físicos na Santa Casa de Misericórdia em São Paulo, a classe hospitalar foi reconhecida como modalidade de ensino, somente em 1994, pelo Ministério da Educação e Cultura - MEC por meio da política da educação especial e normalizadas no período de 2001 a 2002 através de documentos reguladores, a saber: Diretrizes Nacionais para Educação Especial na Educação Básica - DNEE (2001) e Classe hospitalar e atendimento pedagógico domiciliar: orientações e estratégias (2002). A primeira classe hospitalar no país surgiu na cidade do Rio de Janeiro no início da década de 1950 no Hospital Municipal Jesus que se tornou referência nacional na área de educação especial transitória e mantêm suas atividades em funcionamento até os dias de hoje (2019).

De acordo com a DNEE (2001) o atendimento educacional especializado pode ocorrer fora do espaço escolar. Essas diretrizes conceituam classe hospitalar como:

Serviço destinador a prover, mediante atendimento especializado, a educação escolar a alunos que estão impossibilitados de frequentar as aulas em razão de tratamento de saúde que implique internação hospitalar ou atendimento ambulatorial (DNEE, 2001, p. 51).

As classes hospitalares reconhecem os direitos humanos quando se trata de estudantes que estão em situações de tratamento de alguma enfermidade, e se encontram fragilizados em hospitais sem condições de irem à escola. Então, é a escola que vai até eles. Nessa ocasião, as aulas podem acontecer nas enfermarias ou no leito hospitalar, levando conhecimento as pessoas hospitalizadas. Para tanto, nas classes hospitalares devem oferecer recursos tecnológicos que são fundamentais para auxiliar no ensino-aprendizagem a saber: livros didáticos e paradidáticos, notebooks, tablets, câmeras fotográficas, computadores com acesso a interntet, jogos, telefones, etc. Neste caso, aparelhos tecnológicos que ajudam a dinamizar o ensino quando utilizados de forma adequada sob a supervisão do professor, porque são fortes aliados para dinamizar o ensino e combater o tédio no ambiente obscuro de um hospital.

Nas classes hospitalares o pedagogo deve trabalhar com atividades lúdicas, pois tratase daquelas divertidas, criativas, e de finalidades pedagógicas, como: jogos, brinquedos,

Saberes Pedagógicos, Criciúma, v. 5, nº 1, janeiro/abril 2021. - Curso de Pedagogia - UNESC 


\section{SABERES PEDAGÓGICOS}

Revista do Curso de Graduaçào de Pedagogia - Unesc

ISSN 2526-4559

encenações e outras. São atividades prazerosas sem a obrigatoriedade imposta pela rotina escolar de modo formal como as provas e trabalhos. Elas são planejadas e estimulam as crianças a respeitarem regras e condutas sociais, proporcionando facilidades de adquirirem autoconhecimento e contribuem para a descoberta de novos pontos de vista a partir da interação com outras pessoas.

A importância das classes hospitalares surgiu a partir do momento em que profissionais perceberam que crianças e adolescentes hospitalizados tinham o direito de educação. A criança mesmo hospitalizada continua em um pleno processo de desenvolvimento, necessitando de uma educação comprometida. Esse atendimento não é só para crianças com deficiências, mas também, para crianças ou adolescentes que entram no hospital sem previsão de saída, como por exemplo, quando estão fazendo radioterapia ou quimioterapia. $\mathrm{O}$ atendimento em classes hospitalares chega a melhorar a saúde das crianças, visto que esquecem um pouco que estão em um ambiente isolado, fora do convívio com colegas e família.

Essa proposta é para que a criança perceba que mesmo nesse ambiente ela pode ter a escola perto e que pode aumentar seus conhecimentos conceituais, teóricos, técnicos, científicos e valores atitudinais, morais, étnicos, dentre outros. A hospitalização é um momento difícil, tanto para a família, quanto para a criança e adolescente, pois traz preocupações, fragilidades, desânimo, tristeza e sofrimento. Entretanto, a partir do momento que a presença do atendimento educacional acontece, traz alegrias, preenche aquele tempo ocioso que a criança ficava, contribuindo para a autoestima e coragem no enfrentamento da doença. Segundo o documento de estratégias e orientações sobre as classes hospitalares e acompanhamento domiciliar, 2002, p. 11.

$\mathrm{Na}$ impossibilidade de frequência à escola, durante o período sob tratamento de saúde ou de assistência psicossocial, as pessoas necessitam de formas alternativas de organização e oferta de ensino de modo a cumprir com os direitos à educação e à saúde, tal como definidos na Lei e demandados pelo direito à vida em sociedade.

Nessa ótica, a presença de um atendimento pedagógico em um ambiente hospitalar é fundamental para a desenvoltura social e empática de crianças e adolescentes, no contexto que, durante o processo de internação as mesmas estão praticamente dispersas do convívio social e

Saberes Pedagógicos, Criciúma, v. 5, nº 1, janeiro/abril 2021. - Curso de Pedagogia - UNESC 
emocional com outras crianças de sua idade, a não ser com breves visitas de amigos. Por esse viés, a presença de classes hospitalares e sua consonância com a educação voltada à inclusão é fundamental para esse público.

De acordo com Sandroni (2008), é inexorável que a medicina de forma histórica passou a associar o processo de recuperação de um paciente apenas com seu aspecto físico, algo que é intrínseco a disseminação de uma sociedade que apenas visa lucro, corroborada pelo processo de globalização. Assim, fatores sociais foram completamente relacionados, contribuindo para um aumento no mal-estar dos enfermos nesse ambiente que, na maioria das vezes, não acolhe bem seus pacientes.

Isso ocorre por causa da presença de pessoas doentes que ficam aglomeradas em uma mesma enfermaria que não são familiares e que se encontram em um estado de desânimo e sentimento de tristeza, um espaço físico desconfortável e que as vezes não está bem higienizado. Ademais, existe o medo constante de contaminações e do paciente adquirir alguma infecção por vírus ou bactérias, como também, é afetado o estado psicológico e espiritual em que torna-se frequente a angústia e a síndrome do pânico por estar num ambiente em que muitas pessoas morrem, etc. Consequentemente, todos esses fatores podem atenuar o processo de recuperação do paciente hospitalar.

Nesse sentido, para amenizar o sofrimento de crianças e adolescentes, assim como, de seus familiares e amigos, é necessário que se promova no hospital um ambiente menos técnico e que se intensifique sentimentos como a solidariedade, esperança, generosidade, fé, carinho, perseverança, sinceridade, dedicação e amor por parte dos profissionais que prestam serviços nessa instituição. Segundo Oliveira (2013) a origem da possível classe hospitalar no Brasil está vinculada ao mesmo tempo com o surgimento do ensino especial desse país, porque os asilos para alienados ajudam a compreender o pertencimento ao qual a escolarização em hospitais se enquadrou quando finalmente se fez regulamentada como uma modalidade de ensino. 


\section{AS CLASSES HOSPITALARES NO BRASIL: LEGISLAÇÃO E DESENVOLVIMENTO}

Nesse contexto, com a atual vigência das leis associadas a essa problemática no Brasil atual, é importante a atuação de classes hospitalares para possibilitar, entre diversos benefícios, o acesso à escolaridade. Com isso, analisando a atuação dessas classes, é perceptível sua importância para a fluidez no processo de desenvolvimento pedagógico para alunos que se encontram hospitalizados, sendo alicerces para a inclusão dos mesmos, permitindo que não se atrasem devido a entraves de saúde, que colaboram para melhorias tanto após a sua alta, quanto a uma possível reincidência nesse ambiente hospitalar (SANDRONI, 2008).

Por essa análise, medidas governamentais foram tomadas para diminuir essa sistematização da medicina, justamente devido à falta de amparo psicológico dos pacientes que foram desprezados, ou não tratados com a devida atenção e carinho, aderindo a uma relação extremamente técnica e mecânica com o paciente. Logo, preocupado com essa realidade, no ano de 2002, o Ministério da Saúde promulgou uma série de medidas denominado - Programa Nacional de Humanização do atendimento (PNHAH). Esse documento diz respeito a relevância da sensibilidade da esfera hospitalar para as vertentes humanitárias, e não somente das nuances técnicas da medicina (FONTES, 2004).

Esse documento possui como finalidade procurar e organizar estratégias de cunho organizacional para que as mesmas possam efetuar uma considerável melhora na relação entre os funcionários do hospital com o desenvolvimento psicológico do paciente, em todo o seu processo de recuperação, inclusive após sua alta. Medidas que são altamente benéficas para a humanização e fluidez do processo de empatia entre o profissional da saúde e paciente, da interdisciplinaridade entre os profissionais, e também do hospital com a comunidade, procurando direcionar um funcionamento eficiente do Sistema de Saúde do Brasil. (Programa Nacional de humanização no Atendimento Hospitalar, 2002).

Medidas assim são relevantes, porque presencia-se no Brasil um atendimento público a saúde de forma deficitária. Pois, a maioria da população sofre quando procura um centro de saúde ou um hospital por causa da superlotação, infraestrutura ineficiente com carência de profissionais e espaço físico inadequado. É comum observar pessoas esperando em corredores

Saberes Pedagógicos, Criciúma, v. 5, nº1, janeiro/abril 2021. - Curso de Pedagogia - UNESC 
para serem atendidos porque não há enfermarias suficientes e, consequentemente, muitas delas morrem por falta de Unidade de Terapia Intensiva - UTI, dentre outros problemas.

De acordo com a legislação brasileira, o processo de educação e amparo pedagógico é um direito de toda criança e adolescente, inclusive para os que estão hospitalizados. Assim, as classes hospitalares devem estar em paralelo a esse direito que é constitucional, como embasa a Constituição Federal de 1998, no seu artigo 205, o qual determina que:

A educação, direito de todos e dever do Estado e da Família, será promovida e incentivada com a colaboração da sociedade, visando ao pleno desenvolvimento da pessoa, seu preparo para o exercício da cidadania e sua qualificação para o trabalho. (BRASIL, 2014, p. 59)

Com base no exposto, todo cidadão brasileiro tem o direito a educação, como forma para contribuir para o desenvolvimento como ser humano que necessita viver com qualidade. Além disso, o decreto Lei n. 1044/69 delimita que discentes que se encontram na condição de tratamento especial, tem direito a realizarem suas atividades em casa, com o devido acompanhamento pedagógico, que devem estar sempre simultaneamente com a sua saúde e limitações no período que se luta contra a doença. Seguindo essa lei, fica evidente a necessidade de um auxílio pedagógico também alinhado as classes hospitalares.

Tal segmentação de amparo pedagógico, é conhecida juridicamente como classe hospitalar, fomentada pelo Ministério da Educação, por intermédio da efetivação da Política Nacional de Educação Especial (MEC/SEESP, 1994). Esse documento delimita que a educação para os pacientes, quando internados seja efetuada por meio de salas organizadas no hospital ou ainda em seu quarto, pois dependendo do problema de saúde que o paciente esteja enfrentando, é possível que possua dificuldades de locomoção.

Nesse sentido, é relevante que a formação de um profissional da pedagogia também contemple essa realidade, porque a sua atuação não está limitada apenas ao espaço interno restrito entre as quatro paredes representadas pela murada da escola. O pedagogo deve estar qualificado para atuar no ambiente hospitalar caso necessite, pois trata-se de um local onde o aluno se encontra vulnerável, tanto no aspecto físico, quanto no emocional. Por essa razão, é importante a presença desse profissional para ajudar a criança e adolescente a manter seu

Saberes Pedagógicos, Criciúma, v. 5, nº1, janeiro/abril 2021. - Curso de Pedagogia - UNESC 
aprendizado escolar mesmo estando passando por dificuldades físicas e emocionais. (MENEZES, 2004).

\section{O PEDAGOGO, A FAMÍlIA E O ALUNO/PACIENTE}

A prática é fundamental para que o pedagogo consiga aplicar os conceitos teóricos e técnicos aderidos em sua formação. Então, é primordial que em seu processo de estágio não apenas o ambiente escolar seja seu alvo, mas também, ele tenha a oportunidade de interagir e ministrar aulas para os alunos que encontram-se em ambientes hospitalares. (VASCONSCELOS, 2015). Nesse contexto, o pedagogo terá um desafio ainda maior, porque terá que atuar em um ambiente hostil, caso seja necessário, enfrentando também as dificuldades que perpetuam na área da saúde pública. A pessoa hospitalizada sente um impacto emocional negativo, então, é importante que o pedagogo hospitalar trabalhe com alegria e receba informações focadas em coisas boas.

Vale ressaltar que a realidade de analisar o contexto social da relação efetiva e social entre os alunos e docentes nas classes hospitalares são advindas da demora na recuperação e aspectos psicológicos encontrados nesses alunos, assim como, ao considerável atraso acadêmico que a falta desse vínculo ocasiona. Logo, o atendimento escolar no ambiente hospitalar possui como empecilho a sobreposição e alcance dos entraves que são enfrentados por uma criança ou adolescente que está com problemas de saúde, como por exemplo, tédio, depressão, baixa estima, tristeza, distanciamento de brincadeiras que gosta, afastamento dos colegas e de atividades rotineiras, etc.

Diante dessa situação de dificuldades no ambiente escolar os conteúdos escolares devem ser adaptados ao interesse dos alunos de forma que os mesmos sejam encorajados a gostar de estudar, e sintam-se bem com a presença do professor, para que ajude a minimizar os problemas causadas pela doença. Dessa forma, deve envolver recursos tecnológicos que dinamizem e despertem o interesse do aluno/paciente a não repudiar essas aulas no ambiente hospitalar. Tendo em vista que essa realidade está presente na grande maioria dos hospitais do Brasil, a atuação de um profissional da pedagogia nessa instituição, tem sido um ápice tanto para o paciente quanto para a sua família. Desse modo, é indubitável uma considerável melhora no

Saberes Pedagógicos, Criciúma, v. 5, nº 1, janeiro/abril 2021. - Curso de Pedagogia - UNESC 
processo de recuperação do paciente/aluno, do seu desempenho acadêmico e desenvolvimento da autoestima.

De acordo com Fonseca (2003) o principal alicerce do processo de amparo no ambiente hospitalar é o de âmbito pedagógico e educacional às necessidades da melhoria psicológica e cognitivo das crianças e adolescentes, visto que existem as más condições que esse ambiente pode ocasionar para os mesmos, porque se encontram sem possibilidade de relações sociais com sua família e amigos próximos. A pessoa hospitalizada deve ter ao seu redor familiares estimulantes e esperançosos que encoraje a criança e o jovem a acreditar na sua recuperação, estimulando-os com apoio emocional para dá segurança e conforto psicológico para que seu desenvolvimento não seja prejudicado. Pois, nas interações sociais a emoção é algo contagiante, isto é, uma pessoa alegre é capaz de fazer o outro se sentir bem quando interage.

Como fomenta Fontes (2008), o processo de intervenção hospitalar causa a criança e ao adolescente um distanciamento de todas as suas atividades de rotina, e consequentemente, isso resulta numa piora em seu estado de saúde. Devido ao estágio que uma criança está em constante desenvolvimento, essa condição pode contribuir negativamente na constituição de sua formação pessoal, cognitiva e psicomotora. Além disso, a doença causa um estado de impotência na criança, fator que colabora para uma acentuação de seu quadro. Diversas pesquisas apontam que o aspecto psicológico é relevante para a recuperação dos pacientes. Logo, o apoio da família e amigos possui importância e as classes hospitalares reforçam esse apoio de forma significativa diante da situação de vulnerabilidade física e psicológica em que se encontra o aluno/paciente.

A emoção é base da inteligência de uma pessoa, seu suporte e seu vínculo com as outras pessoas. Ao se envolver em atividades lúdicas e brincadeiras a criança hospitalizada sente alegria e esse momento funciona como uma fuga de uma realidade de sofrimento, ela altera o estado psicológico em que está vivendo, adquirindo mais estímulos para conseguir uma recuperação mais rápida. A autoestima é construída na relação entre raciocínio e emoção, sendo capaz de ajudar ou atrapalhar no aprendizado. Nessa ótica, é importante que o pedagogo hospitalar, os amigos, a equipe médica e os familiares trabalhem para que a autoestima da criança permaneça elevada, porque a qualidade de seu aprendizado será melhor. O recebimento de carinho e afeto é fundamental para melhoria do estado psicológico da criança,

Saberes Pedagógicos, Criciúma, v. 5, nº 1, janeiro/abril 2021. - Curso de Pedagogia - UNESC 


\section{SABERES PEDAGÓGICOS}

Revista do Curso de Graduaçào de Pedagogia - Unesc

ISSN 2526-4559

consequentemente, ela terá mais motivação para um aprendizado significativo nas classes hospitalares.

Entretanto, para que ocorra mudanças significativas para um aumento nas classes hospitalares no Brasil é preciso empenho dos gestores de hospitais e envolvimento do Estado. Dessa forma, está presente na sociedade as relações de poder. Para que a classe hospitalar seja concretizada como uma prestação de serviço na sociedade é necessário mobilização dos familiares, requerendo de seus representantes políticos empenho na ampliação da prestação desse serviço.

Portanto, é fundamental a implementação das classes hospitalares para o acompanhamento pedagógico do aluno/paciente, tendo em vista que ainda são poucos os hospitais no país que possuem esse espaço de aprendizado e cidadania. Segundo Ramos (2012) no Brasil, oficialmente, há somente 141 hospitais que oferecem a oportunidade de crianças e adolescentes prosseguirem com seus estudos. Assim, é necessário sensibilidade e compromisso por parte dos administradores públicos que criam as políticas sociais para intervir positivamente na implementação das classes hospitalares no Brasil de forma mais abrangente para possibilitar sua expansão nesse país de dimensões continentais.

\section{CONSIDERAÇÕES FINAIS}

Com base no exposto, pode ser dito que o bom relacionamento entre professor e aluno é essencial para a construção de um ambiente seguro, confortável e propício para o ensinoaprendizagem. Nesse elo afetivo estão incluídos fatores como amizade, confiança, respeito e autoestima. Quando se trata do aluno/paciente que está no hospital, a atenção deve ser maior, porque o estudante vivencia momentos delicados, de vulnerabilidade física e psicológica, necessitando de muito apoio e encorajamento para que apesar das dificuldades ele continue estudando, e principalmente, se fortaleça para não perder o gosto de viver. Logo, um relacionamento de afinidade entre professor e aluno contribui para elevar a autoestima e pode ajudar no restabelecimento de saúde do enfermo.

Vale ressaltar que por serem parte de uma vertente empírica de observação, é inerente $\mathrm{o}$ anseio de promover o direito à escolarização da criança e do adolescente em condições de

Saberes Pedagógicos, Criciúma, v. 5, nº1, janeiro/abril 2021. - Curso de Pedagogia - UNESC 


\section{SABERES PEDAGÓGICOS \\ Revista do Curso de Graduaçào de Pedagogia - Unesc \\ ISSN 2526-4559}

saúde adversas e direcionar essa realidade a melhoria de seu processo de aprendizagem, mesmo em um ambiente tão inóspito, como o hospital. Nesse sentido, neste trabalho foi feita uma revisão de literatura, porque buscou-se informações científicas sobre classes hospitalares, contemplando a leitura de artigos publicados sobre a referida temática, assim como documentos norteadores da legislação nacional, dentre outras fontes. Então, a medida que aprofundou-se no suporte teórico, debateu-se a temática, explicitando uma visão crítica a respeito do assunto.

Portanto, a classe hospitalar é uma iniciativa louvável e espera-se que os atendimentos, sejam ampliados ao longo dos anos, expandindo-se para outros locais do país, além das grandes metrópoles. Deseja-se, também, que atinjam as classes sociais com menor poder aquisitivo financeiro, porque existem muitas crianças e adolescentes em vulnerabilidade física, emocional e social nos hospitais brasileiros necessitando de acompanhamento educacional. Vale ressaltar que, para um eficiente funcionamento das classes hospitalares um fator fundamental é a capacitação do professor, porque ele é um sujeito indispensável a esse processo, tendo em vista que o educador deve conquistar a confiança do estudante/paciente, que muitas vezes, se encontra deprimido e precisa da solidariedade humana, generosidade, carisma, afetividade de um profissional de educação para interagir e repassar conteúdos de forma suave, dinâmica e atrativa, e principalmente, com amor.

Ademais, as classes hospitalares podem estar ligadas a uma questão política, pois para que elas ocorram é necessário uma reivindicação da sociedade para que o Estado implemente essa política pública. Logo, promover políticas sociais é uma forma de contribuir para que diminua a desigualdade social no Brasil, visto que este país possui muita injustiça social, como por exemplo, desigualdades que expressam o preconceito e descriminação com negros, indígenas, mulheres, homossexuais, pessoas em vulnerabilidade social, como também, pessoas com necessidades especiais.

\section{REFERÊNCIAS BIBLIOGRÁFICAS}

BRASIL. Ministério da Educação. Classe hospitalar e atendimento pedagógico domiciliar: estratégias e orientações. Secretaria de Educação Especial. Brasília: MEC; SEESP, 2002.

BRASIL. Constituição 1988. Constituição da República Federativa do Brasil. 43 ed. Brasília. Câmara dos deputados, edições câmara, 2014.

Saberes Pedagógicos, Criciúma, v. 5, nº 1, janeiro/abril 2021. - Curso de Pedagogia - UNESC 


\section{SABERES PEDAGÓGICOS \\ Revista do Curso de Graduaçào de Pedagogia - Unesc \\ ISSN 2526-4559}

BRASIL, Ministério da Educação. Diretrizes nacionais para a educação especial na educação básica. Secretaria de Educação Especial - MEC; SEESP, 2001.

BRASIL. Ministério da Educação. Resolução CNE/CP No 1, de 15 de maio de 2006. Resolução CNE/CP 1/2006. Diário Oficial da União, Brasília, 16 de maio de 2006, Seção 1, p. 11.

BRASIL, Ministério da Educação. Secretaria de Educação Especial. Política Nacional de Educação Especial. Brasília: MEC, SEESP, 1994.

FONTES, Rejane de Souza. A reinvenção da escola a partir de uma experiência instituinte em hospital. Educação e Pesquisa, maio/agosto. Vol.30, no.2, 2004.

FONTES, Rejane de Souza. Da classe à pedagogia hospitalar: a educação para além da escolarização. Revista Linhas, Florianópolis, v. 9, n. 1, jan./jun. 2008.

MACHADO, Jucilene; CAMPOS, Jurema. Relação professor - aluno: um diferencial na classe hospitalar. XI Congresso Nacional de Educação. EDUCERE. Curitiba, 2013.

MENEZES. Cinthya Vernizi A. de. A necessidade da formação do pedagogo para atuar em ambiente hospitalar: um estudo de caso em enfermarias pediátricas do hospital de clínicas da UFPR. Dissertação de Mestrado. Florianópolis, 2004.

OLIVEIRA, Tyara Carvalho de. Um breve histórico sobre as classes hospitalares no Brasil e no mundo. XI Congresso Nacional de Educação. EDUCERE. Curitiba, 2013.

RAMOS, Maria Alice de Moura. Classe hospitalar. Revista Ponto Com. 2012. Disponível em: http://revistapontocom.org.br/artigos/classe-hospitalar. Acesso em: 06 mai. 2019.

SANDRONI, Giuseppina Antonia. Classe hospitalar: um recurso a mais para a inclusão educacional de crianças e jovens. Cadernos da Pedagogia - Ano 2, Vol.2, N.3 jan./jul. 2008. 